\begin{tabular}{|c|c|c|}
\hline & Int.J.Curr.Microbiol.App.Sci (2021) 10(12): 334-343 & \\
\hline & $\begin{array}{l}\text { International Journal of Current Microbiology and Applied Sciences } \\
\text { ISSN: 2319-7706 Volume } \mathbf{1 0} \text { Number } \mathbf{1 2} \mathbf{( 2 0 2 1 )} \\
\text { Journal homepage: } \underline{\text { http://www.ijcmas.com }}\end{array}$ & 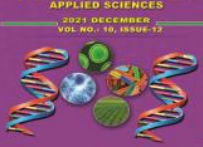 \\
\hline $\begin{array}{l}\text { EXCELLENT } \\
\text { PUBLISHERS }\end{array}$ & & \\
\hline
\end{tabular}

\title{
Sodium Azide Mutagen Affecting Acetyl CoA Carboxylase Sequence and Fatty Acids Production
}

\author{
Eman Tawfik $^{1 *}$ and Rania A. Ellethy ${ }^{2}$ \\ ${ }^{1}$ Department of Botany and Microbiology, ${ }^{2}$ Department of Chemistry, Faculty of Science, \\ Helwan University, Egypt \\ *Corresponding author
}

\section{A B S T R A C T}

\section{Keywords}

ACC gene; GC-MS; Jalview; Multiple sequence alignment; RAPD-PCR;

Sodium azide mutagen

\section{Article Info}

Received: 06 November 2021 Accepted:

05 December 2021 Available Online: 10 December 2021
A biotic stress due to sodium azidemay inhibit bacterial growth, but also can induce some physiological reactions and some fatty acids production. Escherichia coli is Gram-negative bacteria carries Acetyl-CoA gene which is translated into Acetyl-CoA carboxylase (ACC) "a biotin-dependent enzyme" that catalyzes the irreversible carboxylation of acetyl-CoA to produce malonyl-CoA. This compound is the first step in fatty acid production. Different concentrations of sodium azide mutagen were applied to E. coli to estimate the variation in Acetyl-CoA gene sequence comparing to control. The sequencing results were subjected to TCOFFEE tool in Jalview software to assess the multiple sequence alignment. As a measure for gene variation due to mutation treatment, we estimated the fatty acids produced from the mutant bacterial strains comparing to control. The GC-MS profile of the fatty acids concluded that both control and $250 \mu \mathrm{g} / \mathrm{ml}$ mutant bacteria showed the highest concentrations of some fatty acids, where $125 \mu \mathrm{g} / \mathrm{ml}$ mutant bacteria showed complete inhibition in fatty acid production. Besides, RAPD-PCR molecular marker was performed to estimate the general genetic variation in the mutant $E$. coli comparing to control. Sodium azide treatment resulted in a total polymorphism percentage of $77.97 \%$. This percent explained the high genetic variation in the total genome content of azide-mutant $E$. coli comparing to control. The net results from this work that in a certain concentration of sodium azide treatment $(250 \mu \mathrm{g} / \mathrm{ml})$, the production of some essential fatty acids increased.

\section{Introduction}

Induced chemical mutation is a way to make genetic variation leading to new varieties with better traits. Induced mutations also used provide a new source of resistance to both abiotic and biotic stress factors whereby a new resistant variety can be developed. Sodium azide $\left(\mathrm{NaN}_{3}\right)$ is a chemical mutagen and is one of the most powerful mutagens in plants and microorganisms. Its application is inexpensive and easy, and makes mutation to enhance or inhibit their traits according to their responses. The efficiency of mutant production depends 
on many conditions like treatment period and concentration of azide.

It creates point mutation and damages the chromosomes and thus produces tolerance in the organism for numerous adverse conditions (El-Mokademand Mostafa, 2014; Suprasanna et al., 2015). Sodium azide is known as oxidative stress-inducing agent which inhibits cytochrome oxidase to impair the mitochondrial electron transport chain and increases oxidative stress (Garg et al., 2020).

Molecular markers are essential technique to estimate the genetic variation resulted from abiotic chemical stresses treatments. There are many molecular markers such as random amplified polymorphic DNA (RAPD), amplified fragment length polymorphism (AFLP) and inter simple sequence repeats (ISSR).

They were used to estimate the frequency of genomic polymorphism among and between different organisms (El-Khishin et al., 2009; Saker et al., 2011). For example, RAPD-PCR gained much popularity because it is simple, doesn't require of prior information on nucleotide sequence. RAPD-PCR can be performed with a very small amount of genomic DNA. RAPD technique is simple, efficient, reliable and an economical means of cultivar identification and diversity analysis (Fan et al., 2012).

The specific genes pathways are changed in response to stress may vary according to the type of stressor. The differential network of genes affected by various stressors is key to understand the molecular mechanisms of the stress response machinery. Oxidative stress has been involved in the evolution of many diseases like diabetes, cancer, and cardiovascular and neurodegenerative disorders (Garg et al., 2020; Kumar et al., 2015; Liguori et al., 2018).
Acetyl-CoA carboxylase (ACCase) is an expressed enzyme that catalyzes the first step of fatty acid formation, the carboxylation of acetyl-CoA to malonyl-CoA. Heteromeric ACCase consists of four subunits in prokaryotes, where in eukaryotes it is homomeric ACCase and composed of a single large polypeptide.

The ACCase level is at least transcriptionally and post-transcriptionally controlled during organism development. This enzyme catalyzes the first committed step of fatty acid synthesis, and not only control of the enzyme level but also control of its activity is important for organism life (Sauer A, Heise, 1984; Konishi et al., 1996; Sasaki and Nagano, 2004).

The aim of this work was to study the effect of sodium azide as examples for chemical mutagen on the in vitro culture of $E$. coli (DH5- $\alpha$ ). Besides, it aimed to produce genetic variation estimated by RAPD-PCR as a molecular marker to detect this variation.

Also, study the effect of $\mathrm{NaN}_{3}$ on ACC gene which is responsible for biodiesel production via enhancing the fatty acid analysis. The estimation of mutant ACC gene was performed by multiple sequence analysis tool in bioinformatics.

\section{Materials and Methods}

\section{Bacterial Culture and Sodium Azide Preparation}

Different concentrations of sodium azide mutagen were prepared (Control, 125, 250 $\mu \mathrm{g} / \mathrm{ml})$. These concentrations were inoculated in nutrient agar media supplemented with $100 \mu \mathrm{g} / \mathrm{L}$ ampicillin antibiotic compared to control. Escherichia coli (E. coli $(\mathrm{DH} 5 \alpha)$ ), containing ACC gene ligated to pMiniT, was inoculated in each mutant NA media and incubated at $37^{\circ} \mathrm{C}$ for $24 \mathrm{~h}$. 
DNA isolation and RAPD-PCR Molecular Marker

A total genomic DNA from mutant and control bacterial culture was isolated following (Doyle J J, Doyle, 1990) protocol, with some modification. RAPD-PCR reaction was carried out in Biometra thermocycler according to (Roehrdanz R. L. and Flanders, 1993). The reaction mixture was carried out in a total volume of $25 \mu \mathrm{l}$ containing $12.5 \mu \mathrm{l}$ Red Taq master mix (Biolene), $2 \mu$ l of genomic DNA, $1 \mu 1$ for each primer (Biosearch, \#P 1-

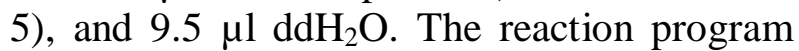
was 40 cycles of the following steps: Denaturation for $30 \mathrm{sec}$ at $94^{\circ} \mathrm{C}$, annealing 30 sec at $35^{\circ} \mathrm{C}$, and extension for $1 \mathrm{~min}$ at $72^{\circ} \mathrm{C}$. After that, one step of the final extension at $72^{\circ} \mathrm{C}$ for $10 \mathrm{~min}$ was then cooling at $4^{\circ} \mathrm{C}$. The amplified PCR product was run on 1.2\% agarose gel compared to (New England Biolab, \#N3232S) 1bp ladder.

\section{ACC Gene Detection in Bacteria}

ACC gene was detected using PCR reaction with forward and reverse primers designed by SnapGene software. The primers are: forward primer: 5'-TATCGGTGATAATCAAAGCA TC-3' and reverse primers 5'- CATTTCAG TGACAGGGTGCT-3, with melting temperature of $50^{\circ} \mathrm{C}$.

\section{Sequencing for Mutant Gene}

Samples from all mutants were sequenced in GATC Company for sequencing which uses the ABI 3730xl DNA sequencer by using forward and reverse sequences, by combining the traditional Sanger with the new 454 technology. A nucleotide blast search was performed with the sequences using sequence alignment by NCBI blast (5) and Geneious software. The similarity/identity value determined from the pair wise comparison of the resulting genes sequence with the data on NCBI. Geneious compares the entered sequence to vast database of sequences and gives a percent value of similarity making it possible to confirm the presence of a given sequence.

\section{Multiple Sequence Alignment}

The ACC mutant gene sequences were obtained from sequencing and then aligned in the database. The graphical image was obtained using Jalview (ver. 2.11.1.3), which is a free program for multiple sequence alignment editing.

\section{Total Lipids Extraction and GC-MS Analysis}

The total fatty acids were extracted from $E$. coli cells according to protocol of Politz et al., (2013). The resulted fractions were analyzed using Gas Chromatography - Mass Spectroscopy (GC-MS). Mass spectra were recorded using Shimadzu GCMS-QP2010 (Koyoto, Japan) equipped with Rtx-5MS fused bonded column ( $30 \mathrm{~m}$ x $0.25 \mathrm{~mm}$ i.d. x 0.25 $\mu \mathrm{m}$ film thickness) (Restek, USA) equipped with a split-split-less injector. The initial column temperature was kept at $50^{\circ} \mathrm{C}$ for 3 min (isothermal) and programmed to $200^{\circ} \mathrm{C}$ at a rate of $15^{\circ} \mathrm{C} / \mathrm{min}$, and kept constant at $200^{\circ} \mathrm{C}$ for 5 min (isothermal). Then the Temperature was programmed to $240{ }^{\circ} \mathrm{C}$ at a rate of $3{ }^{\circ} \mathrm{C} / \mathrm{min}$, and kept constant at $240{ }^{\circ} \mathrm{C}$ for 10 min (isothermal).

Finally, the temperature was programmed to $300{ }^{\circ} \mathrm{C}$ at a rate of $4{ }^{\circ} \mathrm{C} / \mathrm{min}$, and kept constant at $300^{\circ} \mathrm{C}$ for $10 \mathrm{~min}$ (isothermal). Injector temperature was $280^{\circ} \mathrm{C}$. Helium carrier gas flow rate was $1.41 \mathrm{ml} / \mathrm{min}$. All the mass spectra were recorded applying the following condition: (equipment current) filament emission current, $60 \mathrm{~mA}$; ionization voltage, $70 \mathrm{eV}$; ion source, $220^{\circ} \mathrm{C}$. Diluted samples $(1 \% \mathrm{v} / \mathrm{v})$ were injected with split mode (split ratio $1: 15)$. 


\section{Results and Discussion}

\section{Molecular Marker}

Genetic stability of mutated organisms has a great practical utility and commercial implications. In this study, we estimated the fingerprinting profiles of the regenerated culture by RAPD to confirm if the plantlets were genetically stable or not. A total of 10 random decamer-RAPD primers were tested for initial screening, among them only 5 primers gave clear and reproducible bands. The number of polymorphic bands ranged from 2 bands with B07 primer, to 6 polymorphic bands with both P8 and N8 primers (Table 1).

These 5 primers produced a total number of 29 bands with 22 polymorphic bands resulted in a total polymorphism percentage of $77.97 \%$ (Fig. 1). The total molecular weights of all bands were ranged from 160-1554 bp. The total similarity matrix (Table 2) which represented in dendrogram (Fig. 2) illustrated that the $250 \mu \mathrm{g} / \mathrm{ml}$ mutant is more related to control $E$. coli strain.

\section{Mutant ACC Detection in Bacteria}

The genetic study will determine where the gene coding for the ACC production is conferred. This will encourage the manipulations of these genes for better fatty acids production for large scale applications.PCR for ACC detection was performed and the presence of the gene was confirmed in control and mutants E. coli strains (Fig. 3).These bands were sequenced and the results were in silico aligned using TCOFFEE Multiple Sequence Alignment in Jalview software. The alignment (Fig. 4) showed some homology and some differences in the mutant gene sequences.

\section{GC-MS for Fatty Acid from Mutant $E$. coli}

GC/MS analysis of fatty acids extracted from E. coli represented with total ion chromatogram in Fig.5 and results compiled in Table (3) revealed the identification of 8 compounds, representing (more than $30 \%$ ) of the total peak area of chromatogram. The major compounds were Bis(2-ethylhexyl) phthalate, Pyrrolo[1,2-a]pyrazine-1,4-dione, hexahydro-3-(2-methylpropyl)-, Benzene, 1,2,3-trimethyl-. It was noticed that all compounds' concentrations decreased with $125 \mu \mathrm{g} / \mathrm{ml}$ mutant treatment. While, in 250 $\mu \mathrm{g} / \mathrm{ml}$ mutant treatments, some concentrations decrease and others increased. The compounds which increased in concentration were Benzene, 1,2,3-trimethyl-, Benzene, 1-ethyl-2methyl-, Benzene, 1,2,3-trimethyl- and Hexadecane.

Table.1 Primer Data analysis of RAPD-PCR bioassay with different azide mutant E. coli.

\begin{tabular}{|c|c|c|c|c|c|c|}
\hline No. & Name & seq & $\begin{array}{c}\text { Total no. } \\
\text { of bands }\end{array}$ & $\begin{array}{c}\text { Polymorphic } \\
\text { bands }\end{array}$ & $\begin{array}{c}\text { Polymorphism } \\
\text { \% }\end{array}$ & $\begin{array}{c}\text { Size } \\
\text { range bp }\end{array}$ \\
\hline p1 & B07 & 5'-AGATCGAGCC-3 & 3 & 2 & 66.67 & $160-1554$ \\
\hline p2 & B12 & 5'-TTCGAGCCAG-3' & 8 & 5 & 62.5 & $285-1500$ \\
\hline p3 & C1 & 5'-GGAGCCCAG-3' & 3 & 3 & 100 & $181-1125$ \\
\hline p4 & P8 & 5'-ACCTCAGCTC-3' & 7 & 6 & 85.71 & $216-1370$ \\
\hline P5 & N8 & 5'-CCTTGACGCA-3' & 8 & 6 & 75 & $300-1488$ \\
\hline & \multicolumn{2}{|c|}{ Total } & 29 & 22 & 77.97 & \\
\hline
\end{tabular}


Table.2 Similarity matrix among azide mutant E. coli based on RAPD-PCR analysis

\begin{tabular}{|c|c|c|c|}
\hline & Control & $\mathbf{1 2 5} \boldsymbol{\mu g} / \mathbf{m l}$ Mutant & $\mathbf{2 5 0} \boldsymbol{\mu g} / \mathbf{m l}$ Mutant \\
\hline Control & 100 & 25.78 & 40.54 \\
\hline $\mathbf{1 2 5} \boldsymbol{\mu g} / \mathbf{m l}$ Mutant & 25.78 & 100 & 32.3 \\
\hline $\mathbf{2 5 0} \boldsymbol{\mu g} / \mathbf{m l}$ Mutant & 40.54 & 32.3 & 100 \\
\hline
\end{tabular}

Table.3 Chemical composition of fatty acids and hydrocarbons of Azide-mutant E. coli.

\begin{tabular}{|c|c|c|c|c|}
\hline \multirow{2}{*}{ S.No. } & Compounds & \multicolumn{3}{|c|}{ Area \% } \\
\cline { 3 - 4 } & & Control & $\begin{array}{c}\mathbf{1 2 5} \boldsymbol{\mu g} / \mathbf{m l} \\
\text { Mutant }\end{array}$ & $\begin{array}{c}\mathbf{2 5 0} \boldsymbol{\mu g} / \mathbf{m l} \\
\text { Mutant }\end{array}$ \\
\hline $\mathbf{1}$ & & 14.53 & 5.34 & 10.25 \\
\hline $\mathbf{2}$ & Bis(2-ethylhexyl) phthalate & 10.48 & 2.61 & 10.29 \\
\hline $\mathbf{3}$ & $\begin{array}{c}\text { Pyrrolo[1,2-a]pyrazine-1,4-dione, } \\
\text { hexahydro-3-(2-methylpropyl)- }\end{array}$ & 7.65 & 2.30 & 8.73 \\
\hline $\mathbf{4}$ & Benzene, 1,2,3-trimethyl- & 5.54 & 1.25 & 6.59 \\
\hline $\mathbf{5}$ & Benzene, 1-ethyl-2-methyl- & 4.75 & 0.09 & 1.98 \\
\hline $\mathbf{6}$ & Phenol, 2,4-bis(1,1-dimethylethyl)- & 4.36 & 0.91 & 6.01 \\
\hline $\mathbf{7}$ & Benzene, 1,2,3-trimethyl- & 3.80 & 0.94 & 5.33 \\
\hline $\mathbf{8}$ & Hexadecane & 3.36 & 0.71 & 1.23 \\
\hline
\end{tabular}

Fig.1 Gel banding pattern of RAPD-PCR for mutant E. coli. (a) B07 primer, (b) B12 primer, (c) C1 primer, (d) P8 primer and (e) N8 primer. (C: control E. coli; $1: 125 \mu \mathrm{g} / \mathrm{ml}$ azide mutant $E$. coli; $2: 250 \mu \mathrm{g} / \mathrm{ml}$ azide mutant E. coli)

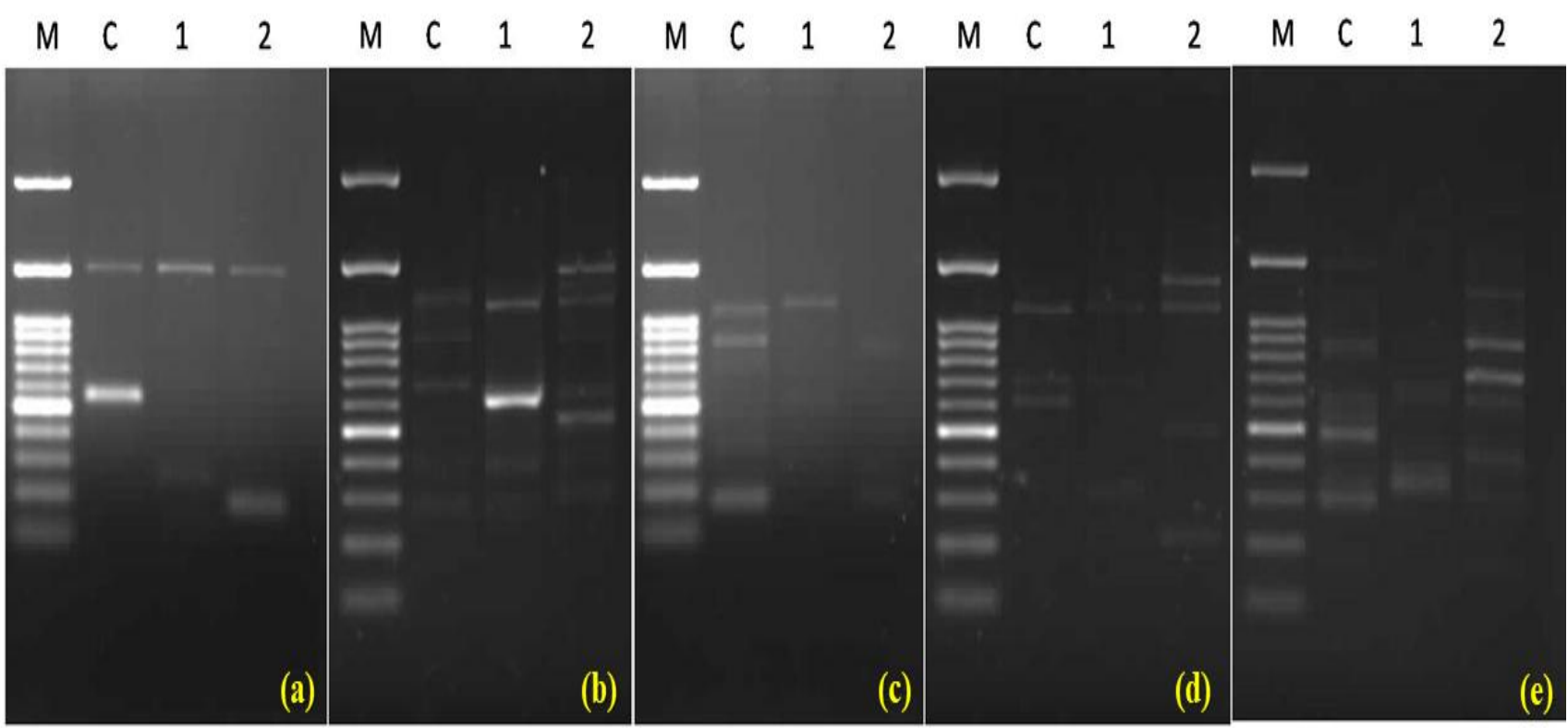


Fig.2 Dendrogram among azide mutant $E$. coli based on RAPD-PCR analysis

\begin{tabular}{lll}
\hline $1.11 \mathrm{E} 4$ & $7.11 \mathrm{E3}$ & 0
\end{tabular}

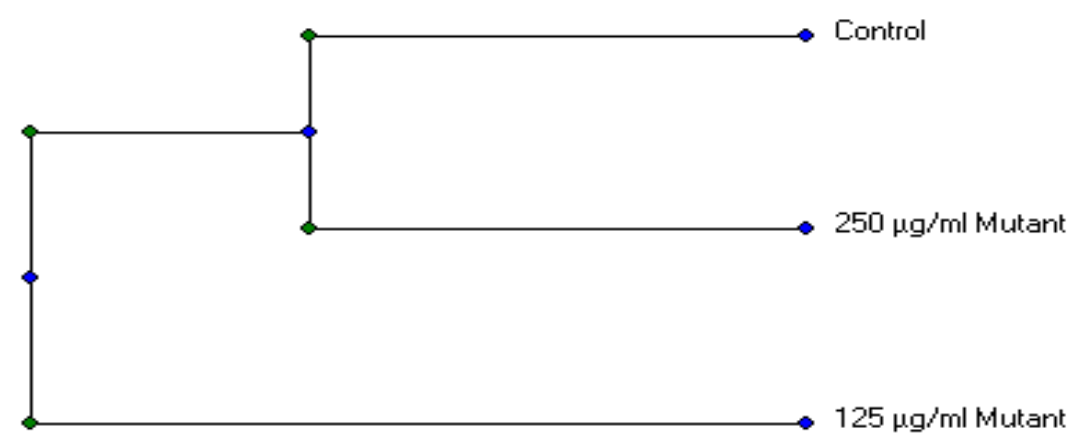

Fig.3 Gel electrophoresis for ACC Gene detection in mutants and control bacterial strains. C: control E. coli, 1: mutant E. coli with $125 \mu \mathrm{g} / \mathrm{ml}$ Sod. Azid, 2: mutant E. coli with $250 \mu \mathrm{g} / \mathrm{ml}$ Sod. Azid

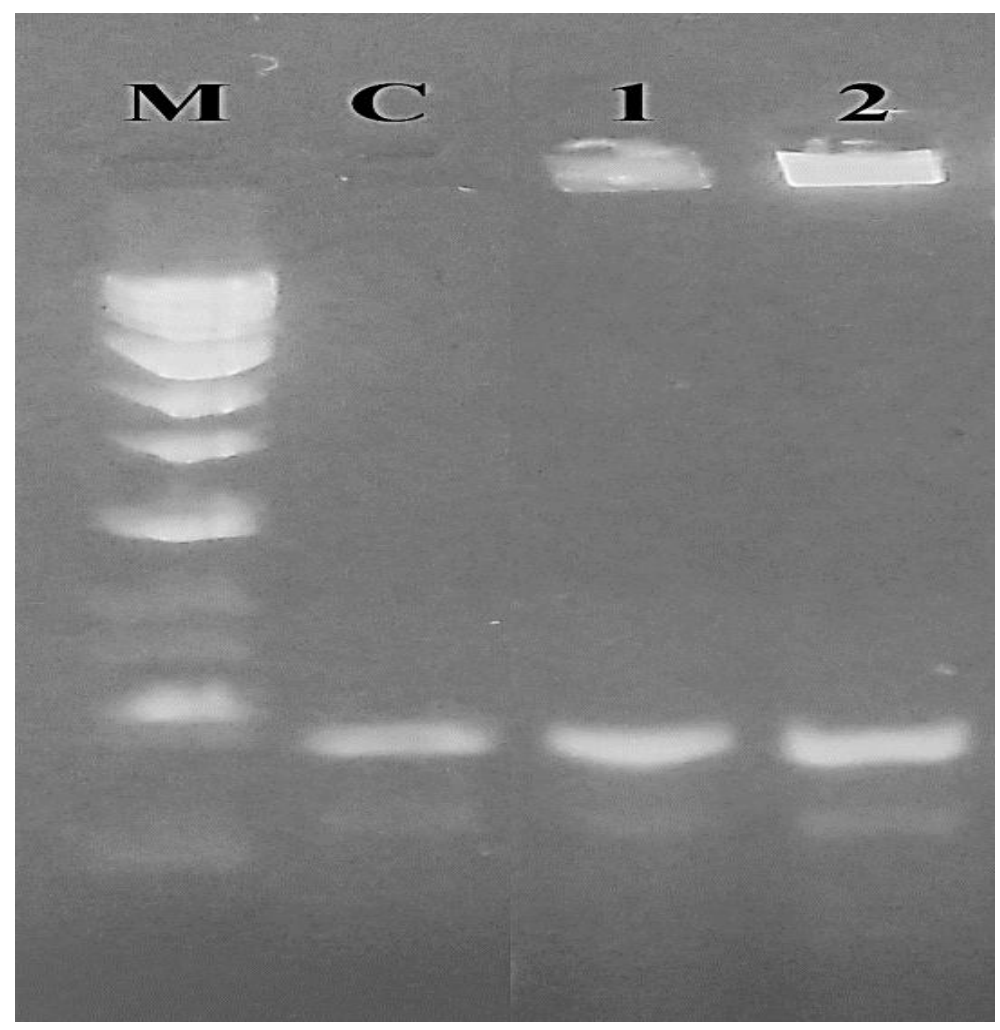


Fig.4 Homology analysis of ACC mutant and control sequences in silico using Jalview software.

191217-047_CO4_E1-group 11_1F-group 11_ab 11906/-1986 191217-047_O02_EB-group 11_ IF-group 11.ab $11843 /$ 1-1843 191217-047_G04_EC-group 11_2F-group 11.ab 12565/1-2565

Consensus

Oocupanoy

191217-047_CO4_E1-group11_1F-group11.ab 11986/1-1986 191217-047_OO2_EB-group 11__F-group 11.ab 11843/1-1843 191217-047_GO4_EC-group 11_2F-group 11.ab 12555/1-2555

Consensus

Oecupancy

191217-047_CO4_E1-group11_1F-group11 ab11986/1986 191217-047_OO2_EB-group 11_ TF-group 11.ab 118431 1-1843 191217-047_GO4_EC-group 11_2F-group 11.ab 12555/1-2555

Consensus

191217-047_CO4_E1-group11_1F-group 11.ab11996/-1986 191217-047_OO2_EB-yroup 11__F-group 11.ab 11843/1-1843 191217-047_G04_EG-group 11_2F-group 11.ab 12555/1-2555

Consensus

Decupancy

191217-047_CO4_E1-group 11_1F-group 11_ab 119061-1986 191217-047_O02_EB-yroup 11_1F-group 11.ab 11843/1-1843 191217-047_G04_ECgroup 11_2F-group 11.ab 12565/1-2565

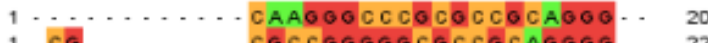
$1 . \mathrm{CG}$.......... CGCGGGGGGCGCCGCAGGGG. 22 1 AACCAAGGTATTTTCCGTGACTTACGTAAGACAT 34

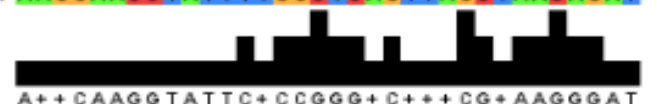

$\mathrm{A}++$ CAAGG TATTC+CCGGG+C+++CG+AAGGGAT

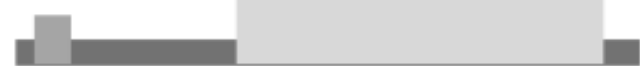

21 - GAGCGGGTCGTGGAGCGCGAG... GAAGACCT 49 23 . ATGCGGGTCGTGGAGCGCGAG..... GAAGACGT 51 35 TCTTCTOTTATCOOAGAOCAATTOACOAATTOTT TOB प"प

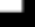

T+ TOCOOOTCOTOOAOCOCOAOTOACOAAOAC+T

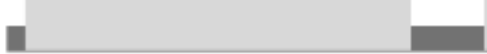

50 CCGGGAGCAGATGGAACGCGCGATTTCCGAGGCT 83 52 CCOGOAGCAGATGOAACOCOCOATTTCCOAGOCT B5 69 ATTGCCGACCGCGGAAGGAATCCTTTCOGCAATA 102

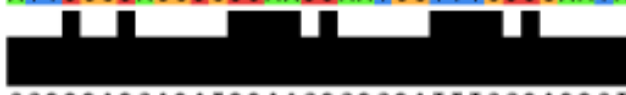

CCGGGAGCAGATGGAACGCGCGATTTCCGAGGCT

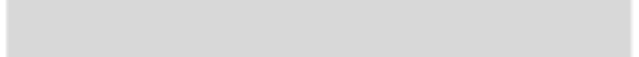

84 ACT. TCGOCGTTTGOCGATGOTTCGOTCTTTAT 115 80 ACT- TCOOCOTTTOOCOATOOTTCOOTCTTTAT 117 103 AGTATTTGGTGTGGGCAGTTATCTCATCCCTTCT 130

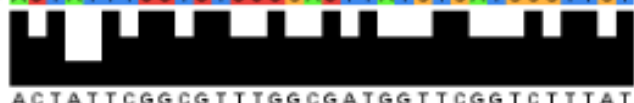

ACTATTCGGCGTTTGGCGATGGTTCGGTCTTTAT

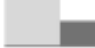

$116 \ldots . . .6$ COAAAAAT TCOTOACCTCOCCOCOCCA 142 $118 \ldots . . .$. CGAAAAAT TCGTGACCTCGCCGCGCCA 144 137 ITTAGTGCTCATTGTTATTGCCAACCGCGGGCCA 170

Fig.5 GC-MS Chromatogram of fatty acids of control E. coli carrying ACC gene.

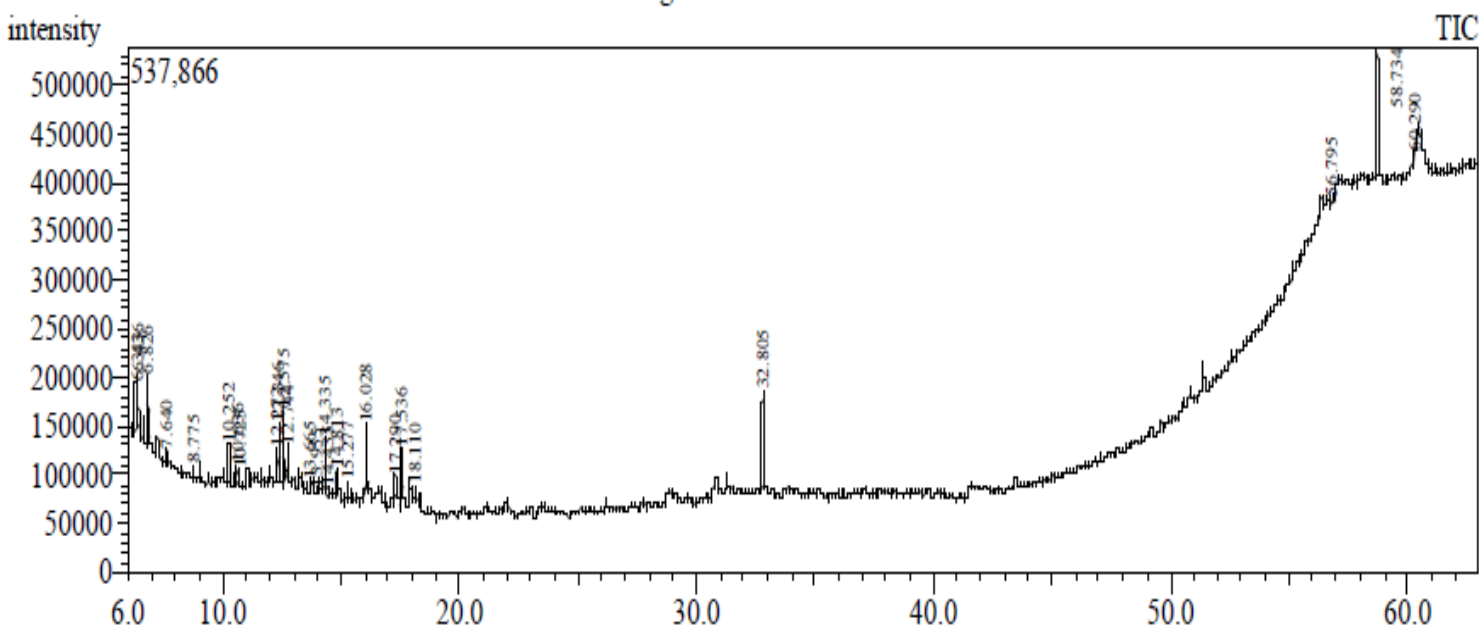




\section{Molecular Marker}

Applying molecular analysis of different bacterial strains has been well documented by Afshari et al., (2016) who estimated the genetic diversity and clonal relationships of 110 isolates of E. coli from calves with septicemia and diarrhea along with humans with urinary tract infection using RAPD-PCR. Vancheva et al., (2018) applied RAPD-PCR to investigate the heterogeneity in the populations of the species causing bacterial spot-on pepper in Bulgaria and Macedonia. Also, Zare et al., (2019) assessed the genotypic polymorphism among Staphylococcus aureus isolate were recovered from banknotes, foods, human infections and bovine mastitis milk by RAPD-PCR.

Okore et al., (2017) also screen 65 bacterial isolates for biosurfactant production using RAPD and to identify the molecular sizes of the genes coding for the biosurfactant production. This study based on clones ACo genes by Fathy et al., (2021) who transform ACo gene into $E$. coli in order to be transformed into cyanobacterial strain.

\section{GC-MS for Fatty Acid from Mutant E. coli}

Not only fatty acids which are considered as an indicator for bio-diesel and biofuel production, but also, generally many hydrocarbons assist them. Some hydrocarbons are considered as a measure of the combustibility of biodiesel. Examples for these hydrocarbons in this work were Benzene and hexadecane.

Oursel et al., (2007) applied GC-MS to determine the lipid composition of membranes from LM 3118, a wild-type, K12 laboratory strain of E. coli. Also, estimated fatty acid distributions in three different bacteria, Escherichia coli, Francisella novicida and Bacillus subtilis, studied by using GC-MS.
Different fatty acid profiles were observed in the three bacteria. Also, Cifré et al., (2013) characterized large amounts of unsaturated fatty acids in Bacillus cereus. Sodium azide is a chemical mutagen that may inhibit bacterial growth. However, it can enhance the fatty acids production which is essential for biodiesel production. Escherichia coli carrying Acetyl-CoA gene which is translated into Acetyl-CoA carboxylase (ACC) that produced some compounds essential for fatty acid production. Different concentrations of sodium azide mutagen were applied to E. coli to estimate the variation in Acetyl-CoA gene sequence comparing to control. The sequencing results were subjected to TCOFFEE tool in Jalview software to assess the multiple sequence alignment. As a measure for gene variation due to mutation treatment, we estimated the fatty acids produced from the mutant bacterial strains comparing to control.

The GC-MS profile of the fatty acids concluded that both control and $250 \mu \mathrm{g} / \mathrm{ml}$ mutant bacteria showed the highest concentrations of some fatty acids, where 125 $\mu \mathrm{g} / \mathrm{ml}$ mutant bacteria showed complete inhibition in fatty acid production. The essential fatty acids produced were $\operatorname{Bis}(2-$ ethylhexyl) phthalate, Pyrrolo[1,2-a]pyrazine1,4-dione, hexahydro-3-(2-methylpropyl)-, Benzene, 1,2,3-trimethyl- and Hexadecane. Besides, 5 RAPD primers were used to estimate the general genetic variation in the mutant E. coli comparing to control resulting in total polymorphism percentage of $77.97 \%$.

\section{Abbreviations}

ACo: Acetyl CoA; ACC: Acetyl-CoA carboxylase; GC-MS: Gas ChromatographyMass Spectroscopy; MSA: Multiple sequence alignment; RAPD-PCR: Random Amplified Polymorphic DNA-Polymerase Chain Reaction. 


\section{Acknowledgment}

The author would like to thank Dr. Ahmed Hassan (Botany and Microbiology Department) and Dr. Salim Mohammed (Chemistry Department), Faculty of Science, Helwan University; for their help during practical work and data explanation.

\section{References}

Afshari, A., Rad, M., Seifi, H. A., and Ghazvini, K. 2016. Genetic variation among Escherichia coli isolates from human and calves by using RAPD PCR. Iranian Journal of Veterinary Medicine (IJVR). 10(1):33-40.

Cifré, L. C., Alemany, M., de Mendoza, D., and Altabe, S. 2013. Exploring the Biosynthesis of Unsaturated Fatty Acids in Bacillus cereus ATCC 14579 and Functional Characterization of Novel AcylLipid Desaturases. Appl Environ Microbiol. 79(20):6271-6279.

Doyle, J. J., Doyle, J. L. 1990. Isolation of Plant DNA from Fresh Tissue. Focus 12:13-15

El-Khishin, D. A., Abdul Hamid, A., El Moghazy, G., and Metry, E. A. 2009. Assessment of genetically modified potato lines resistant to potato virus $\mathrm{Y}$ using compositional analysis and molecular markers. Res J Agric Biol Sci. 5:261-271.

El-Mokadem, H. E., and Mostafa, G. G. 2014. Induction of mutations in Browallia speciosa using sodium azide and identification of the genetic variation by peroxidase isozyme. Afr $\mathbf{J}$ Biotechnol. 13(1):106-111.

Fan Li, A. B., Ruijuan, Z., Jorge, A. C., Donglin, X., and GailiBaob, R. 2012. Simultaneous detection and differentiation of four closely related sweet potato potyviruses by a multiplex one-step RPCR. USDA-
ARS, National Germplasm Resources Laboratory, Beltsville, MD 20705, USA.

Fathy, W., Essawy, E., Tawfik, E., Khedr, M., Abdelhameed, M. S., Hammouda, O., and Elsayed, K. 2021. Recombinant overexpression of the Escherichia coli acetyl-CoA carboxylase gene in Synechocystis sp. Boosts lipid production. J Basic Micro. 1-9. DOI: 10.1002/jobm.202000656

Garg, M., Poornima, G., and Rajyaguru, P. I. 2020. Elucidation of the RNA-granule inducing sodium azide stress response through transcriptome analysis. Genomics. 112:2978-2989.

Konishi, T., Shinohara, K., Yamada, K., and Sasaki, Y. 1996 Acetyl-CoA carboxylase in higher plants; most plants other than Gramineae have both the prokaryotic and the eukaryotic forms of this enzyme. Plant Cell Physiol. 37:117-122

Kumar, V., Khan, A. A., Tripathi, A., Dixit, P. K., and Bajaj, U. 2015. Role of oxidative stress in various diseases: Relevance of dietary antioxidants, J Pharm Exp Ther. 4:126-132.

Liguori, I., Russo, G., Curcio, F., Bulli, G., Aran, L., Della-Morte, D., Gargiulo, G., Testa, G., Cacciatore, F., and Bonaduce, D. 2018. Oxidative stress, aging, and diseases. Clin Interv Aging. 13:757.

Okore, C., Nwaehiri, L., Mbanefo, O., Ogbulie, T., and Ogbuka, I. 2017. The Use of Random Amplified Polymorphic Dna (Rapd) To Study the Genetic Variation of Biosurfactant Producing Bacteria. Aca J Ssi. 07(03):267-286.

Oursel, D., Loutelier-Bourhis, C., Orange, N., Chevalier, S., Norris, V., and Lange, C. M. 2007. Identification and relative quantification of fatty acids in Escherichia coli membranes by gas 
chromatography/mass spectrometry. Rapid Commun Mass Spectrom. 21: 3229-3233.

Politz, M., Lennen, R., and Pfleger, B. 2013. Quantification of Bacterial Fatty Acids by Extraction and Methylation. Bioprotocol 3(21):e950. DOI: 10.21769/BioProtoc.950.

Roehrdanz, R. L., and Flanders R. V. 1993. Detection of DNA Polymorphisms in Predatory Coccinellids Using Polymerase Chain Reaction and Arbitrary Primers (RAPD-PCR). Entomophaga. 38 (4):479-491

Saker, M. M., Mohamed, A. A., and Aly, A. A. 2011. Comparative analysis of transformed potato microtubers and its non-transformed counterpart using some biochemical analysis along with inter simple sequence repeat (ISSR) marker. Afr J Biotech. 10(34): 64016410.

Sasaki, Y., and Nagano, Y. 2004. Plant Acetyl-CoA Carboxylase: Structure, Biosynthesis, Regulation, and Gene
Manipulation for Plant Breeding. Review. BiosciBiotechnolBiochem. 68(6):1175-1184.

Sauer, A., and Heise, K. P. 1984. Regulation of acetylcoenzyme A carboxylase and acetyl-coenzyme A synthetase in spinach chloroplasts. Z Naturforsch. 39C:268-275.

Suprasanna, P., Mirajkar, S. J. and Bhagwat, S. G. 2015. Induced Mutations and Crop Improvement. Plant Biotechnol. 1: 593-617.

Vanchevaa, T., Stoyanovab, M., TashevaTerzievaa, E., Bogatzevskab, N., and Moncheva, P. 2018. Bacterial, Fungal and Virus Molecular Biology. Molecular methods for diversity assessment among xanthomonads of Bulgarian and Macedonian pepper. Braz J Microbiol. 49S:246-259

Zare, S., Derakhshandeh, A., Haghkhah, M., Naziri, Z., andBroujeni, A. M. 2019. Molecular typing of Staphylococcus aureus from different sources by RAPD-PCR analysis. Heliyon. e02231.

\section{How to cite this article:}

Eman Tawfik and Rania A. Ellethy. 2021. Sodium Azide Mutagen Affecting Acetyl CoA Carboxylase Sequence and Fatty Acids Production. Int.J.Curr.Microbiol.App.Sci. 10(12): 334343. doi: https://doi.org/10.20546/ijcmas.2021.1012.039 